\title{
miR-146a-5p-mediated suppression on trophoblast cell progression and epithelial-mesenchymal transition in preeclampsia
}

\author{
Pingping Peng ${ }^{1,2}$, Huamei Song ${ }^{1,2}$, Chenghong Xie ${ }^{1,2}$, Wenfei Zheng ${ }^{1,2}$, Huigai Ma ${ }^{1,2}$, Dandan Xin ${ }^{1,2}$,
} Jingqiong Zhan ${ }^{1,2}$, Xiaoqing Yuan ${ }^{1,2}$, Aihua Chen ${ }^{1,2}$, Jing Tao ${ }^{1,2}$ and Jufang Qin ${ }^{1,2,3^{*}}$

\begin{abstract}
Objective: This study aims to identify the effect of miR-146a-5p on trophoblast cell invasion as well as the mechanism in preeclampsia (PE).

Methods: Expression levels of miR-146a-5p and Wnt2 in preeclamptic and normal placentae were quantified. Trophoblast cells (HTR-8) were separately transfected with miR-146a-5p mimic, miR-146a-5p inhibitor, pcDNA3.1-Wnt2 or sh-Wnt2, and then the expression levels of miR-146a-5p, Wnt2, and epithelial-mesenchymal transition (EMT)-related proteins (Vimentin, $\mathrm{N}$-cadherin and E-cadherin) were measured. Moreover, the proliferative, migratory and invasive capacities of trophoblast cells were detected, respectively. Dual luciferase reporter assay determined the binding of miR-146a-5p and Wnt2.

Results: Compared with normal placental tissues, the placentae from PE patients showed higher miR-146a-5p expression and lower Wnt2 expression. Transfection of miR-146a-5p inhibitor or pcDNA3.1-Wnt2 exerted pro-migratory and pro-invasive effects on HTR-8 cells and encouraged EMT in HTR-8 cells; transfection with miR-146a-5p mimic or sh-Wnt2 weakened the proliferative, migratory and invasive capacities as well as reduced EMT process of HTR-8 cells. Moreover, Wnt2 overexpression could partially counteract the suppressive effects of miR-146a-5p overexpression on the progression and EMT of HTR-8 cells.
\end{abstract}

Conclusion: miR-146a-5p mediates trophoblast cell proliferation and invasion through regulating Wnt2 expression.

Keywords: Trophoblast cells, miR-146a-5p, Wnt2, Proliferation, Migration, Epithelial-mesenchymal transition

\section{Introduction}

Preeclampsia (PE) is a syndrome of pregnancy characterized by hypertension and proteinuria [1], which is a dominant cause of maternal and perinatal deaths with

\footnotetext{
*Correspondence: qinjufang2020@163.com

${ }^{3}$ Department of Gynecology and Obstetrics, the First People's Hospital of Yichang, the People's Hospital of China Three Gorges University, No. 4, Hudi Street, Xiling District, Yichang 443000, Hubei, People's Republic of China

Full list of author information is available at the end of the article
}

the incidence of 5-7\% [2]. Although the explicit pathogenesis of PE has not been fully understood, impaired spiral artery remodeling, oxygen dysregulation, and increased maternal vascular damage are admittedly considered causative factors of PE [3]. During the first trimester of pregnancy, invasive extravillous trophoblasts (EVTs) are responsible for the nutrient supply demanded by the fetus through remodeling the uterine spiral arteries [4]. Highly invasive EVTs, derived from trophoblast cells by epithelial-mesenchymal transition original author(s) and the source, provide a link to the Creative Commons licence, and indicate if changes were made. The images or other third party material in this article are included in the article's Creative Commons licence, unless indicated otherwise in a credit line to the material. If material is not included in the article's Creative Commons licence and your intended use is not permitted by statutory regulation or exceeds the permitted use, you will need to obtain permission directly from the copyright holder. To view a copy of this licence, visit http://creativecommons.org/licenses/by/4.0/. The Creative Commons Public Domain Dedication waiver (http://creativeco mmons.org/publicdomain/zero/1.0/) applies to the data made available in this article, unless otherwise stated in a credit line to the data. 
(EMT), are able to establish maternal-fetal linkage [5]. In this regard, insufficient acquisition of invasive and migratory capacities by trophoblast cells plays a vital role in the onset of PE. Epithelial-mesenchymal transition (EMT) is a physiological process that gives epithelial cells invasive and migratory potential to become cells with mesenchymal cell morphology and properties $[6,7]$. Moreover, dysregulated EMT of trophoblast cells in PE induces defective migration and invasion [5]. These findings emphasize the demand for disclosing the effective regulators of trophoblast cell progression, especially of trophoblast EMT process.

MicroRNAs (miRNAs), a type of non-coding RNAs with 22 nt in length, are endowed with posttranscriptionally regulatory potential through paring with sequence in the $3^{\prime}$ untranslated region (UTR) of target genes [8]. Many researches have figured out the important roles of miRNAs in trophoblast cell progression. For instance, miR-134 impairs trophoblast cell infiltration in PE through downregulating Integrin Beta 1 (ITGB1) [9]. miR-616-3p upregulation stimulates trophoblast cell growth and migration in PE through inhibiting tissue factor pathway inhibitor 2 (TFPI2) [10]. As a mature miRNA generated by miR-146a, miR-146a-5p shows suppressive effects on the proliferative, invasive and migratory capacities of breast cancer cells [11] and on the EMT process of oesophageal squamous cells [12]. Upregulated miR-146a-5p expression was found in patients with a history of gestational hypertension [13]. In PE patients, downregulation of miR-146a-5p was reported by Hromadnikova et al. [14]. Ding and colleagues instead demonstrated overexpressed miR-146a-5p in placentae from PE patients [15]. The expression pattern of miR-146a-5p in PE is controversial and its biological functions remain to be investigated. Wnt2, one of the Wnt ligands, is a secreted glycoprotein downregulated in PE placentae [16]. Wnt2 is elucidated to promote the proliferation and migration of first trimester trophoblast cells via activating Wnt/ $\beta$-catenin pathway [17]. In this study, the online software StarBase predicted the binding sites of miR-146a-5p in the $3^{\prime}$ UTR of Wnt2, which implied that the interplay of miR-146a-5p and Wnt2 may play a role in regulating trophoblast cell progression.

In the present study, the expression levels of miR146a-5p and Wnt2 in the placentae from patients with $\mathrm{PE}$ were confirmed. The biological functions of miR$146 a-5 p /$ Wnt2 axis were also determined in in vitro experiments. We demonstrated the involvement of miR146a-5p/Wnt2 axis in the trophoblast cell progression and EMT event, which could provide a latent approach for improving the invasive and migratory capacities of trophoblast cells and mitigating PE development.

\section{Materials and methods}

\section{Placental tissue collection}

Collection of placental tissues from normal pregnant female ( $\mathrm{n}=30$; Normal group) and patients with $\mathrm{PE}$ $(\mathrm{n}=30$; PE group) was conducted since January 2018May 2020 at the First People's Hospital of Yichang. Ethics Committee approval from the First People's Hospital of Yichang was obtained after informed written consent was provided by each patient. This study conformed to the principles issued in the Declaration of Helsinki. Clinical data of participants are listed in Table 1 . The collected placental tissues were frozen by liquid nitrogen and preserved at $-80{ }^{\circ} \mathrm{C}$ before further analyses. The diagnosis criteria for PE were as follows [18]: patients had no history of preexisting or chronic hypertension, but exhibited systolic pressure > $140 \mathrm{mmHg}$ or diastolic pressure $>90 \mathrm{mmHg}$ at least 2 occasions, concurrent with proteinuria $(>2 \mathrm{~g}$ per $24 \mathrm{~h}$ in 2 samples obtained at $>4 \mathrm{~h}$ intervals) after 20 weeks of gestation. The exclusion criteria included chronic hypertension, BMI > 24 before pregnancy, heart disease, diabetes, hepatopathy, nephropathy, intra uterine fetal death, fetal chromosomal or congenital abnormalities, and pregnancy following fertility treatment.

\section{Cell culture}

Human trophoblast cell line [HTR-8; American Type Culture Collection (ATCC)] was cultured in RPMI1640 (Thermo Fisher Scientific, MA, USA) supplemented with $10 \%$ fetal bovine serum (FBS; Thermo Fisher Scientific, MA, USA), $100 \mathrm{U} / \mathrm{mL}$ penicillin and $100 \mu \mathrm{g} / \mathrm{ml}$ streptomycin. Human embryonic kidney cells (HEK-293 T; ATCC) were grown in DMEM containing $10 \% \mathrm{FBS}, 100 \mathrm{U} / \mathrm{mL}$ penicillin and $100 \mu \mathrm{g} / \mathrm{ml}$ streptomycin. HTR-8 and HEK-293 T cells were maintained under humidified conditions $\left(37^{\circ} \mathrm{C}, 5 \% \mathrm{CO}_{2}\right)$.

Table 1 Clinical data of normal pregnant women and PE patients

\begin{tabular}{|c|c|c|c|}
\hline Clinical data & Control $(n=30)$ & $\operatorname{PE}(n=30)$ & $P$ values \\
\hline Maternal age (year) & $30.5 \pm 4.8$ & $30.2 \pm 5.1$ & $>0.05$ \\
\hline Maternal weight (kg) & $68.5 \pm 5.9$ & $70.6 \pm 6.8$ & $>0.05$ \\
\hline Gestational age (week) & $38.7 \pm 2.5$ & $36.3 \pm 2.5$ & $<0.05$ \\
\hline $\begin{array}{l}\text { Systolic blood pressure } \\
\text { (mm Hg) }\end{array}$ & $112.5 \pm 7.2$ & $170.3 \pm 8.9$ & $<0.001$ \\
\hline $\begin{array}{l}\text { Diastolic blood pressure } \\
\quad(\mathrm{mm} \mathrm{Hg})\end{array}$ & $75.9 \pm 2.5$ & $118.7 \pm 5.5$ & $<0.001$ \\
\hline Proteinuria (g/day) & Not detected & $4.5 \pm 1.3$ & $<0.01$ \\
\hline
\end{tabular}

PE preeclampsia 


\section{Transfections}

Short hairpin RNA (shRNA) against Wnt2 (sh-Wnt2; $2 \mu \mathrm{g})$, pcDNA3.1 plasmid with Wnt2 overexpression (pcDNA3.1-Wnt-2; $2 \mu \mathrm{g})$, miR-146a-5p mimic (100 nM), miR-146a-5p inhibitor (100 nM), and their negative controls (sh-NC, pcDNA3.1, mimic NC and inhibitor NC) (RiboBio Co., Ltd., Guangzhou, China) were transfected into HTR-8 cells using Lipofectamine 2000 kit (Thermo Fisher Scientific, MA, USA). These cells were accordingly designated into pcDNA3.1 group, pcDNA3.1Wnt2 group, sh-NC group, sh-Wnt2 group, mimic NC group, miR-146a-5p mimic group, inhibitor NC group, miR-146a-5p inhibitor group, miR-146a-5p mimic + pcDNA3.1 group and miR-146a-5p mimic + pcDNA3.1Wnt2 group. Stably transfected cells were maintained in RPMI-1640 and further cultured at $37^{\circ} \mathrm{C}$ and $5 \% \mathrm{CO}_{2}$.

\section{MTT assay}

Following treatment for $24 \mathrm{~h}, 48 \mathrm{~h}, 72 \mathrm{~h}$ and $96 \mathrm{~h}$, cells were counted. Cell suspension $\left(100 \mu \mathrm{L} /\right.$ well, $10^{4}-10^{5}$ cells) was seeded onto a 96 well plate in triplicate, and then the cells were placed at $37{ }^{\circ} \mathrm{C}$ and $5 \% \mathrm{CO}_{2}$. After $20 \mu \mathrm{L}$ of MTT solution ( $5 \mathrm{mg} / \mathrm{mL}$, Sigma, MO, USA) were pipetted into the wells, the cells were further cultured for $4 \mathrm{~h}$ at $37{ }^{\circ} \mathrm{C}$ and $5 \% \mathrm{CO}_{2}$. The medium was removed and DMSO $(150 \mu \mathrm{L} /$ well $)$ was pipetted onto the cells to dissolve the crystal. The absorbance of each group was measured three times and then averaged. Each group had 3 replicate wells.

\section{Colony formation assay}

For colony formation assay, monolayer cells were digested with $0.25 \%$ trypsin, flapped and suspended in $10 \%$ FBS. The cell suspension was seeded onto culture plates containing $10 \mathrm{ml}$ of warm $\left(37^{\circ} \mathrm{C}\right)$ culture medium at gradient densities $(50,100$ or 200 cells per well), after which the cells was dispersed and cultured at $37^{\circ} \mathrm{C}$ under humidified conditions for 2-3 weeks. The incubation was not terminated until colonies could be observed by naked eyes. After the medium was pipetted off, the cells were rinsed twice in PBS and exposed to $5 \mathrm{ml}$ acetic acid/methanol (1:3) for $15 \mathrm{~min}$ and Giemsa stain for 10-30 $\mathrm{min}$. Then, the cells were washed to remove the excess stain and air dried. The culture plate was inverted and overlapped by a transparent film with grid. Finally, the colonies (more than 10 cells) were counted by naked eyes or under a low power microscope to calculate the colony formation rate. Each group had 3 replicate wells.

\section{Transwell invasion assay}

Transwells $(6.5 \mathrm{~mm}$ in diameter; $8 \mu \mathrm{m}$ pore; Corning Costar, Cambridge, MA) were pre-coated with $0.1 \mathrm{ml}$ matrigel $(200 \mu \mathrm{g} / \mathrm{ml}$; BD Bioscience, Franklin Lakes, NJ, USA) and maintained at $37{ }^{\circ} \mathrm{C}$ overnight for gelling. Subsequently, stably transfected HTR- 8 cells $\left(5 \times 10^{4}\right.$ cells/ well) were resuspended and seeded onto the transwells. RPMI-1640 containing 10\% FBS was added into basolateral chamber and cultured $\left(37{ }^{\circ} \mathrm{C}, 5 \% \mathrm{CO}_{2}\right)$ for $24 \mathrm{~h}$. Afterwards, the cells were immersed in $4 \%$ paraformaldehyde for $10 \mathrm{~min}$ and stained (10 min, room temperature) by $0.5 \%$ crystal violet. Invaded cells were photographed under an optical microscope in five random fields. All data were from three independent experiments. Each group was repeated for three times.

\section{Scratch assay}

Scratch assay was conducted as previously described [19]. In brief, HTR-8 cells were seeded in 6-well plates and grew to $90 \%$ confluence. Thereafter, three scratches were made in each well vertically using a $100 \mu \mathrm{L}$ pipette tip, and the cells were washed and cultured in serum free culture medium. A low power phase contrast microscope was used to observe the scratches. After further incubation for $24 \mathrm{~h}$, the scratches were photographed. Migration rate $=($ scratch gap at $0 \mathrm{~h}-$ scratch gap at $24 \mathrm{~h}) /$ scratch gap at $0 \mathrm{~h}$. Each group had 3 replicate wells.

\section{RT-qPCR}

Following cell transfection, HTR-8 cells were lysed in $1 \mathrm{ml}$ Trizol (Thermo Fisher Scientific, MA, USA) to obtain RNA extracts. After quantification, the RNA extracts were reverse transcribed to synthesize cDNA. Relative mRNA and miRNA expression levels were determined by using a fluorescent quantitative PCR kit (Takara, Dalian, China) on quantitative PCR instrument ABI7500 (Applied Biosystems, Shanghai, China). The reactions were performed under the following conditions: predegradation $\left(95{ }^{\circ} \mathrm{C}, 10 \mathrm{~min}\right) ; 40$ cycles of degradation $\left(95{ }^{\circ} \mathrm{C}, 10 \mathrm{~s}\right)$, annealing $\left(60{ }^{\circ} \mathrm{C}, 20 \mathrm{~s}\right)$ and extension $\left(72{ }^{\circ} \mathrm{C}, 34 \mathrm{~s}\right)$. All primers used in this work were synthesized by GENEWIZ, Inc. (Beijing, China) (Table 2). For miRNA and mRNA expression analyses, U6 and GAPDH were used as loading controls. Relative expression was measured using $2^{-\Delta \Delta \mathrm{Ct}}$ method as previously described [20]. $\Delta \Delta \mathrm{Ct}=\left[\mathrm{Ct}_{\text {(target gene) }}-\mathrm{Ct}_{\text {(reference gene) }}\right]_{\text {experimental }}$ group $-\left[\mathrm{Ct}_{\text {(target gene) }}-\mathrm{Ct}_{\text {(reference gene) }}\right]_{\text {control group }}$. Each group had 3 replicate wells.

\section{Western blotting}

Placental tissues and HTR- 8 cells were washed twice with ice-cold PBS, and total protein extracts were obtained from HTR-8 cells lysed in protein extraction lysate $(100 \mu \mathrm{L} / 50 \mathrm{~mL})$. Then, the lysed cell was maintained on ice for $30 \mathrm{~min}$ and centrifuged $(12,000 \mathrm{rpm}, 10 \mathrm{~min})$. The supernatant were aliquoted into $0.5 \mathrm{ml}$ centrifuge 
Table 2 Names and primer sequences of genes of interest and relative internal references

\begin{tabular}{ll}
\hline Name of primer & Sequences $\left(\mathbf{5}^{\prime} \mathbf{- 3}^{\prime} \mathbf{)}\right.$ \\
\hline miR-146a-5p-F & AACCCATGGAATTCAGTTCTCA \\
miR-146a-5p-R & ATCCAGTGCAGGGTCCGAGG \\
Wnt2-F & GGGTCCTACTCCGAAGTAG \\
Wnt2-R & CCTTGGCTACAGGCCCTG \\
Vimentin-F & TCCGCACATTCGAGCAAAGA \\
Vimentin-R & TGAGGGCTCCTAGCGGTTTA \\
N-cadherin-F & AGGGGAGAGGTGCTCTACTG \\
N-cadherin-R & GGGGTAATCCACACCACCTG \\
E-cadherin-F & CGTCGAGCTCTTGACCGAAA \\
E-cadherin-R & TCAAACACCTCCTGTCCTCT \\
GAPDH-F & ACCACAGTCCATGCCATCAC \\
GAPDH-R & TCCACCACCCTGTTGCTGTA \\
U6-F & TCGCTTCGGCAGCACATATAC \\
U6-R & GCGTGTCATCCTTGCGCAG \\
\hline
\end{tabular}

$F$ forward; $R$ reverse

tubes and preserved at $-20^{\circ} \mathrm{C}$ or quantified by BCA kit (Sigma-Aldrich, St. Louis, MI, USA). The protein extracts were degraded in $6 \times$ SDS loading buffer at $100{ }^{\circ} \mathrm{C}$ and separated by SDS electrophoresis. Afterwards, the protein extracts were transferred to membranes in ice-cold transfer buffer $\left(4{ }^{\circ} \mathrm{C}\right)$ for $1.5 \mathrm{~h}$, ant the membranes were immersed in TBST supplemented with $5 \%$ non-fat milk powder for $1 \mathrm{~h}$. The membranes were further incubated in TBST containing primary antibodies against rabbit derived GAPDH (1:10,000, ab181602), Wnt2 (1:500, ab27794), Vimentin (1:2000, ab92547), N-cadherin (1:1000, ab 76,057), and E-cadherin (1:1000, ab40772) (Abcam, MA, USA) overnight at $4{ }^{\circ} \mathrm{C}$. After TBST washing $(3 \times 10 \mathrm{~min})$, the membranes were incubated $(2 \mathrm{~h}$, room temperature) with goat anti rabbit IgG or goat anti mouse IgG (Beijing ComWin Biotech Co., Ltd., Beijing, China). Following TBST washing and color development, protein expression of genes of interest was quantified. Each group was repeated for 3 times.

\section{Dual luciferase reporter assay}

The binding sites of miR-146a-5p in the $3^{\prime} \mathrm{UTR}$ of Wnt2 were predicted by online software StarBase. Accordingly, the wild and mutated sequences of the binding sites were synthesized and cloned into luciferase reporter vectors (Promega) to construct the vectors WT-Wnt-2 and MUT-Wnt-2. Then, the WT-Wnt2 and MUT-Wnt2 were separately cotransfected with miR-146a-5p mimic or miR-146a-5p inhibitor into HEK-293 T cells. These cells were further cultured $\left(48 \mathrm{~h}, 37^{\circ} \mathrm{C}, 5 \% \mathrm{CO}_{2}\right)$ in DMEM, and luciferase activity in each group was determined using a luciferase reporter assay kit (Promega, WI, USA). Each group had 3 replicate wells.

\section{Statistical analysis}

Data analyses were conducted by statistical software SPSS 18.0 (IBM Corp., Armonk, NY, USA) and GraphPad Prism 6.0 (GraphPad Software Inc.) and presented as mean \pm standard deviations (SDs). $T$ test was used for comparisons between two groups and one-way analysis of variance was performed for multiple group analyses. Results were considered significant when $P<0.05$. Each experiment was repeated for three times.

\section{Results}

\section{High miR-146a-5p expression and low Wnt2 expression} in the placentae from PE patients

Initially, the clinicopathological characteristics of 30 normal pregnant women and $30 \mathrm{PE}$ patients were collected and analyzed (Table 1). Analyses of the clinical data in the PE and normal groups revealed that both the systolic and diastolic blood pressures were elevated in the PE group; proteinuria was detected in the PE group, whereas it was not assessed in the normal group (Table 1). Moreover, the gestational age in the PE group was significantly decreased than that in the normal group (Table 1). Furthermore, the expression levels of miR-146a-5p and Wnt2 in placentae from PE and normal pregnant females were assayed. RT-qPCR revealed that miR-146a-5p expression was increased in placentae from $P E$ patients (Fig. $1 \mathrm{~A}, P<0.001$ ). As shown by RT-qPCR and Western blotting, the expression of Wnt2 mRNA and protein was decreased in the PE patients compared with normal pregnant women (Fig. 1B, C, $P<0.01$ ).

\section{miR-146a-5p affects trophoblast cell propagation, invasion and EMT}

To identify the biological functions of miR-146a-5p in trophoblast cells, miR-146a-5p was overexpressed or silenced in HTR-8 cells. RT-qPCR analysis showed higher miR-146a-5p level in the miR-146a-5p mimic group ( $P$ $<0.001$, vs mimic NC group) and lower miR-146a-5p expression in the miR-146a-5p inhibitor group $(P<0.01$, vs inhibitor NC group), whereas the difference in miR146a-5p expression between the mimic NC group and the inhibitor NC group was indistinctive (Fig. 2A). The results indicated the satisfactory transfection of miR146a-5p mimic and miR-146a-5p inhibitor.

To determine the impact of miR-146a-5p on the proliferative, migratory and invasive capacities of HTR-8 cells, MTT, colony formation, Transwell invasion and Scratch assays were performed. Compared with the mimic NC group, the proliferative capacity of HTR- 8 cells was inhibited and the number of colonies was reduced in the 
A

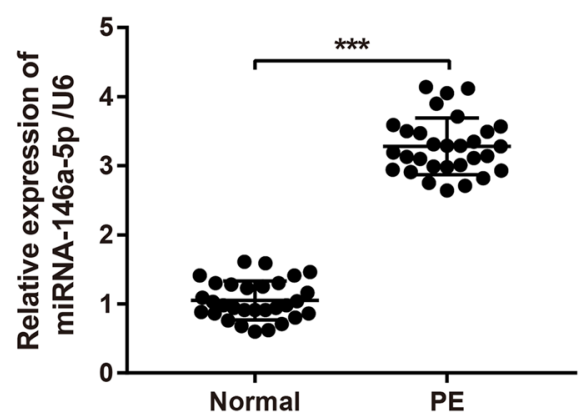

C

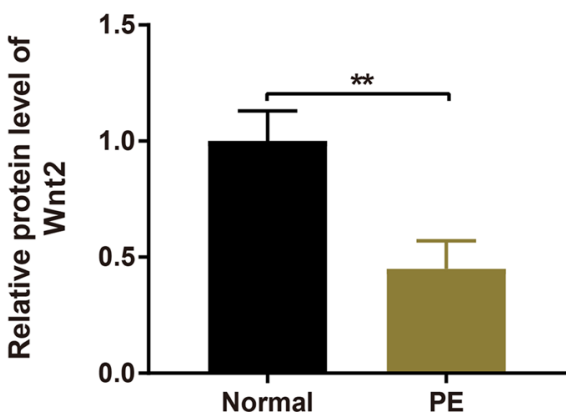

B

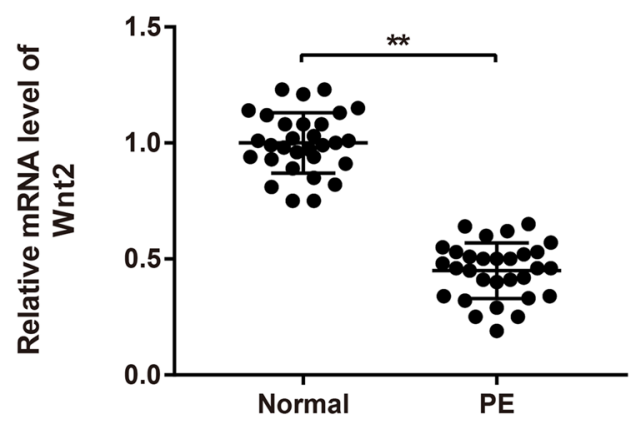

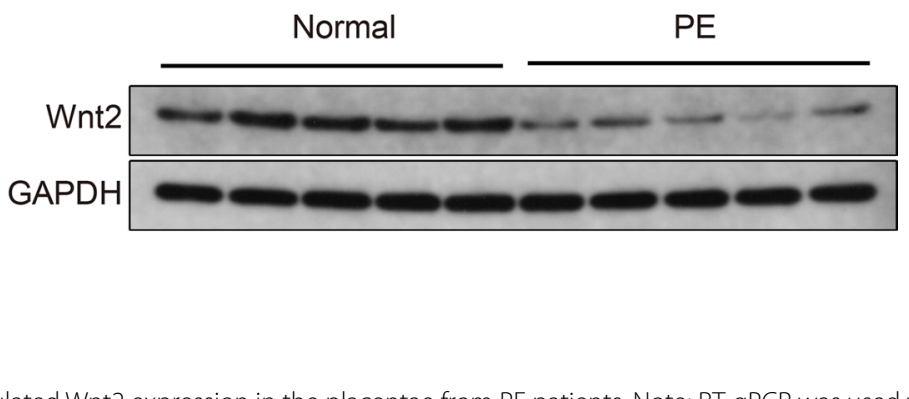

Fig. 1 Upregulated miR-146a-5p expression and downregulated Wnt2 expression in the placentae from PE patients. Note: RT-qPCR was used to measure miR-146a-5p expression in the placentae from normal and PE patients (A); Wnt2 expression was determined by RT-qPCR (B) and Western blotting (C). All data are presented as mean $\pm \mathrm{SDs} ; \mathrm{n}=30,{ }^{* *} P<0.01,{ }^{* * *} P<0.001$. SD standard deviation; $P E$ preeclampsia

miR-146a-5p mimic group (Fig. 2B, C, $P<0.01$ ). Moreover, the invasive and migratory capacities were reduced in the miR-146a-5p mimic group compared with the mimic NC group (Fig. 2D, E, $P<0.01$ ). Furthermore, the miR146a-5p inhibitor group showed increased proliferative, invasive and migratory capacities compared to the inhibitor NC group (Fig. $2 \mathrm{~B}-\mathrm{E}, P<0.01$ ). These observations revealed that miR-146a-5p suppressed the proliferative, migratory and invasive capacities of trophoblast cells.

EMT process reportedly involves in the initiation and development of various human diseases, including PE [21], mainly manifesting as decreased expression of epithelial markers (i.e., E-cadherin) and increased expression of mesenchymal markers (i.e., N-cadherin and Vimentin) [22]. During the process, E-cadherin is converted to $\mathrm{N}$-cadherin, thereby enhancing cell invasion and migration [23]. As detected by RT-qPCR and Western blotting, Vimentin and N-cadherin levels were reduced and E-cadherin expression was elevated in the miR-146a-5p mimic group compared with mimic NC group (Fig. 2F, G, $P<0.05)$. Conversely, the levels of Vimentin and N-cadherin were increased and E-cadherin was decreased in the miR-146a-5p inhibitor group (Fig. 2F, G, $P<0.05$, vs the inhibitor NC group). Taken together, miR-146a-5p suppressed the proliferation, migratory and invasive properties as well as EMT of trophoblast cells.

\section{Wnt2 augments the proliferation, invasion and EMT process of trophoblast cells}

pcDNA3.1-Wnt2 and sh-Wnt2 were introduced into HTR-8 cells to investigate the effect of Wnt2 on trophoblast cells. Transfection of pcDNA3.1-Wnt2 increased Wnt2 expression in HTR-8 cells compared to those transfected with pcDNA3.1, and HTR-8 cells transfected with sh-Wnt2 showed decreased Wnt2 expression compared with the sh-NC group (Fig. $3 \mathrm{~A}, \mathrm{~B}, P<0.01$ ), indicating satisfactory transfection of pcDNA3.1-Wnt2 and sh-Wnt2 in HTR-8 cells.

As exhibited in Fig. 3C, D, the proliferation of HTR-8 cells was enhanced in the pcDNA3.1-Wnt2 group (vs the pcDNA3.1 group), while Wnt2 silencing induced a decrease in HTR-8 cell proliferation (vs the sh-NC group) $(P<0.01)$. Transwell invasion and Scratch assays revealed increased migratory and invasive capacities in the pcDNA3.1-Wnt2 group compared to the pcDNA3.1 group, whereas the migration and invasiveness of HTR-8 cells were reduced after transfection with sh-Wnt2 $(P<0.01)$; significant difference 
$\mathbf{A}_{\text {- mimole }}-$ misanc $\quad$ B
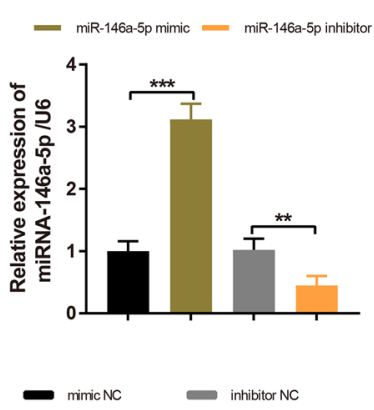

miR-146a-5p mimic $=$ miR-146a-5p inhibitor

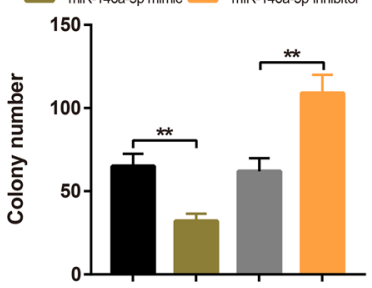

D
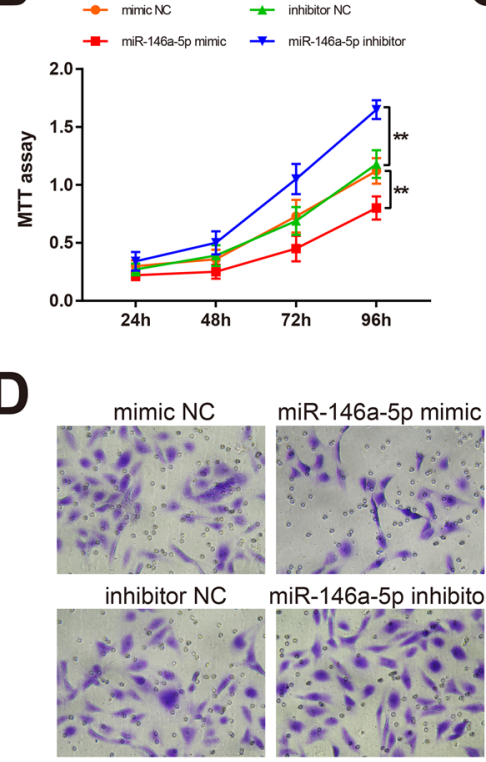

C mimic NC miR-146a-5p mimic
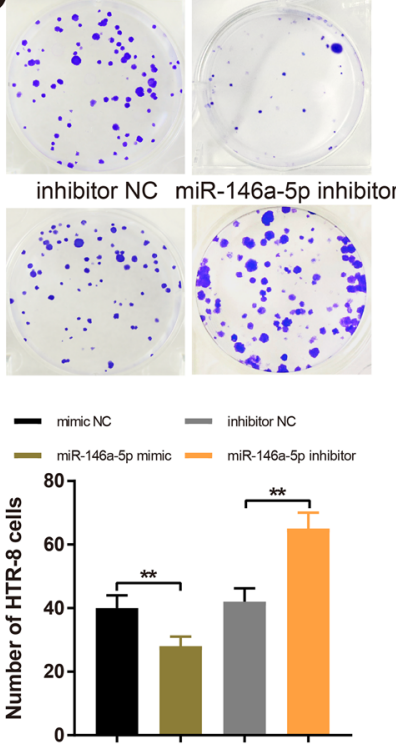

$\mathbf{E}$
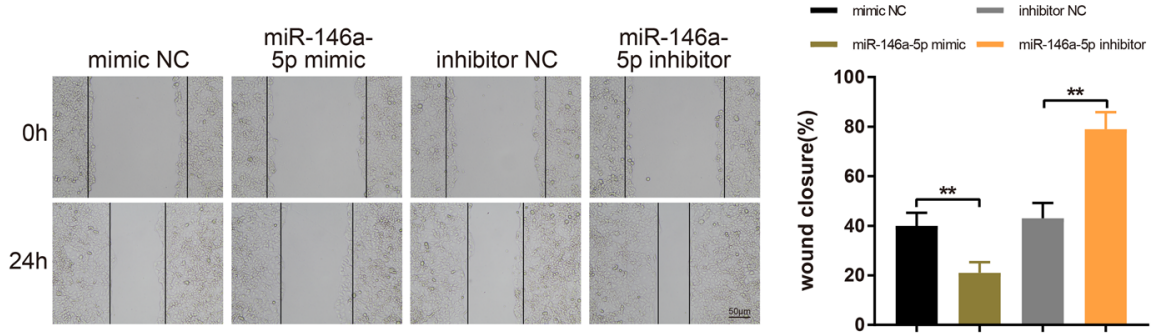

$\mathbf{F}$

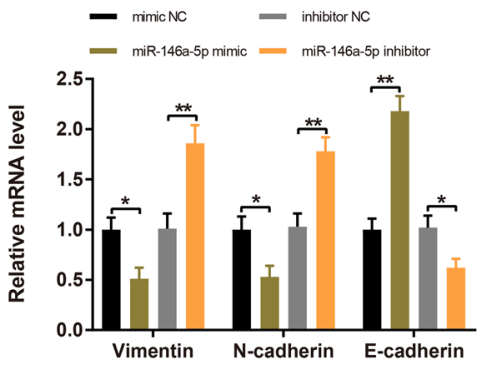

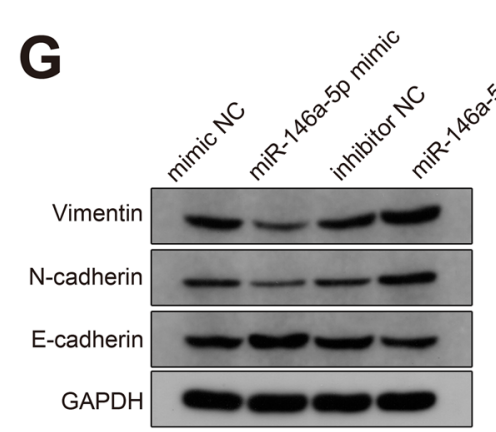

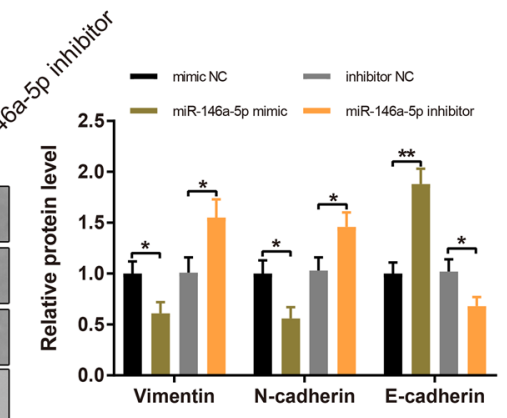

Fig. 2 miR-146a-5p inhibits biological properties and EMT of trophoblast cells. Note: After HTR-8 cells were transfected with miR-146a-5p mimic, miR-146a-5p inhibitor, mimic NC or inhibitor NC, RT-qPCR was used to detect miR-146a-5p expression (A); MTT assay (B) and colony formation assay (C) determined the proliferative capacity of HTR-8 cells; invasiveness of HTR-8 cells as measured by Transwell invasion assay (D); HTR-8 cell migration was evaluated by Scratch assay (E); RT-qPCR and Western blotting examined the expression levels of Vimentin, N-cadherin and E-cadherin (F, G). All data are presented as mean $\pm \mathrm{SD} ; \mathrm{n}=3,{ }^{*} P<0.05$, ${ }^{* *} P<0.01,{ }^{* *} P<0.001$. SD standard deviation; EMT epithelial-mesenchymal transition

in the migration and invasiveness of HTR-8 cells was found neither in the pcDNA3.1 nor in the sh-NC groups (Fig. 3E, F). Moreover, RT-qPCR and Western blot analyses exhibited great increases in Vimentin and $\mathrm{N}$-cadherin levels and a reduction in E-cadherin expression in the pcDNA3.1-Wnt2 group compared with the pcDNA3.1 group, and conversely, transfection with sh-Wnt2 decreased Vimentin and N-cadherin levels and increased E-cadherin expression in HTR-8 cells when compared with the sh-NC group (Fig. 3G, H, $P<$ $0.01)$. These results were indicative of the enhancement of Wnt2 on the proliferative, migratory and invasive capacities and EMT process of trophoblast cells. 


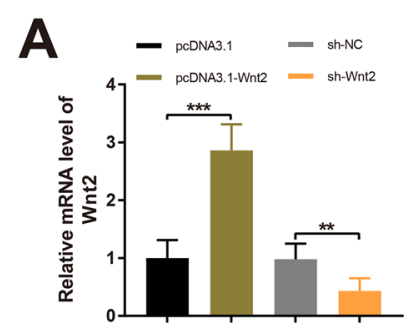

B
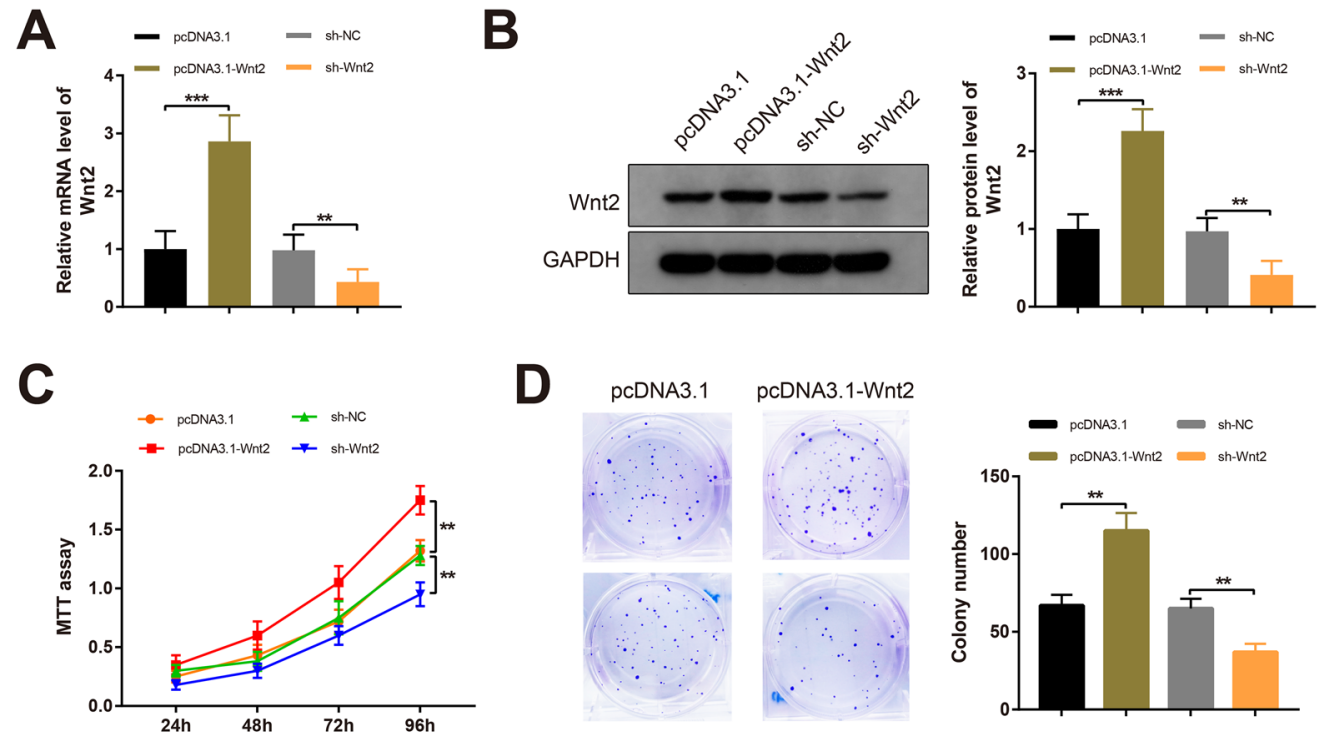

sh-NC

sh-Wnt2
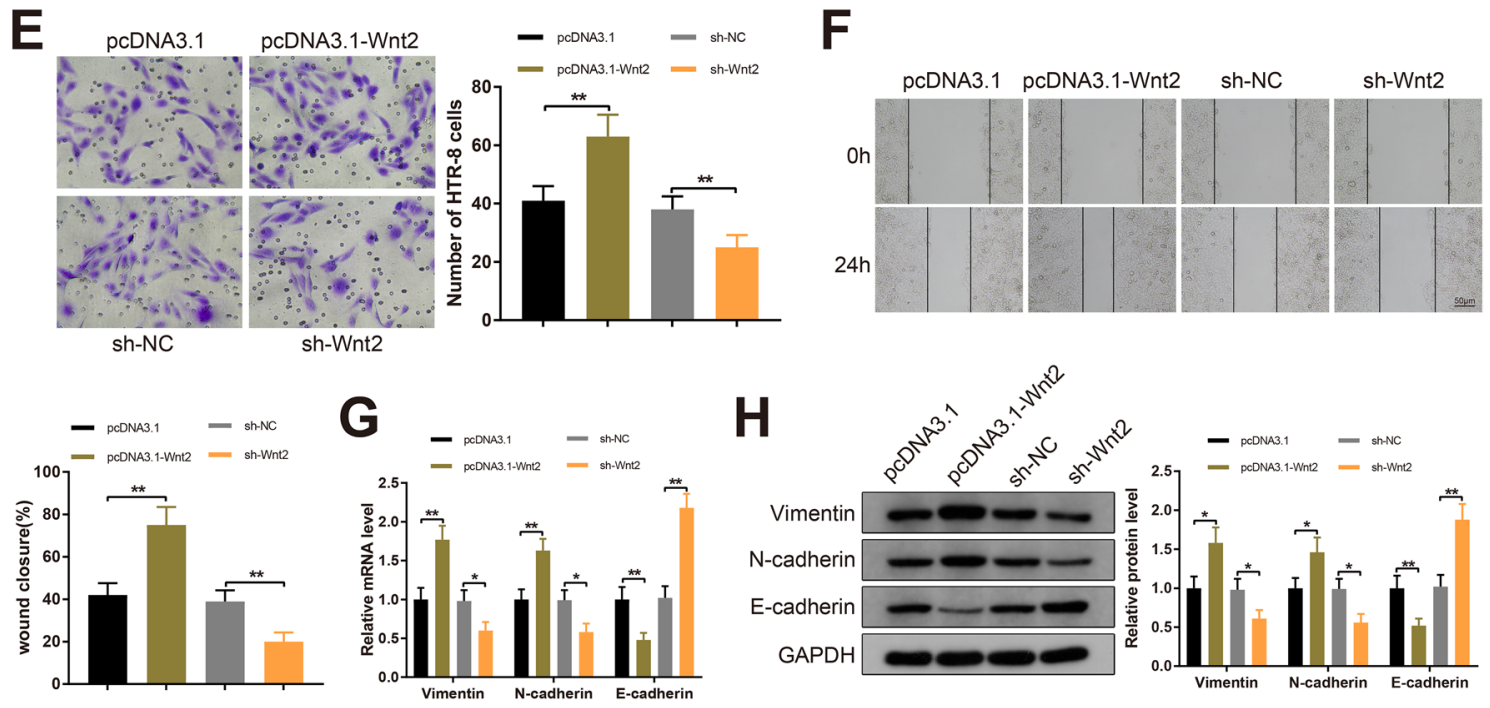

Fig. 3 Wnt2 promotes the proliferation, migration, invasion and EMT of trophoblast cells. Note: pcDNA3.1-Wnt2, sh-Wnt2, pcDNA3.1 or sh-NC was transfected into HTR-8 cells, and then Wnt2 expression was determined by RT-qPCR (A) and Western blotting (B); the proliferative capacity of HTR-8 cells as measured by MTT assay $(\mathbf{C})$ and colony formation assay $(\mathbf{D})$; Transwell invasion assay $(\mathbf{E})$ and Scratch assay $(\mathbf{F})$ assessed the migratory capacity and invasiveness of HTR-8 cells separately; RT-qPCR $(\mathbf{G})$ and Western blot $\mathbf{( H )}$ analyses for EMT-related proteins (Vimentin, N-cadherin and E-cadherin). All data are presented as mean $\pm \mathrm{SDs} ; \mathrm{n}=3,{ }^{*} P<0.05,{ }^{* *} P<0.01,{ }^{* * *} P<0.001$. SD standard deviation; EMT epithelial-mesenchymal transition

\section{Wnt2 is a target of miR-146a-5p}

Online software StarBase probed the binding sites of miR-146a-5p in the 3'UTR of Wnt2 (Fig. 4A). Hence, we hypothesized that miR-146a-5p implicated in the biological properties of trophoblast cells through regulating Wnt2. To test this hypothesis, miR-146a-5p was overexpressed or inhibited in HTR-8 cells. In the miR146a-5p mimic group, the expression of Wnt2 mRNA and protein was reduced compared to the mimic NC group; compared to the inhibitor NC group, Wnt2 expression was enhanced in the miR-146a-5p inhibitor group (Fig. 4B, C, $P<0.01$ ). To investigate whether miR146a-5p could bind to Wnt2, WT-Wnt2 and MUT-Wnt2 (containing 7 mutated binding sites of miR-146a-5p in the 3'UTR of Wnt2) were constructed. The dual luciferase reporter assay suggested that cotransfection of WTWnt2 and miR-146a-5p mimic decreased the luciferase activities of HEK-293 T cells $(P<0.01$, vs the mimic NC 
A

$\overline{\text { WT-Wnt2 }} \quad$ 5'-CUCCCCUCCUGGCGAGUUCUCU-3'

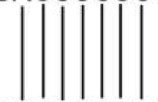

miR-146a-5p 5'-UUGGGUACCUUAAGUCAAGAGU-3'

\section{MUT-Wnt2 5'-CUCCCCUCCUGGCGUCAAGAGU-3}

B

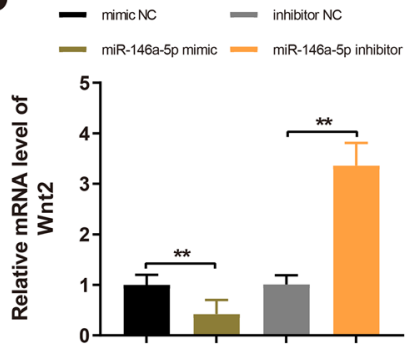

C

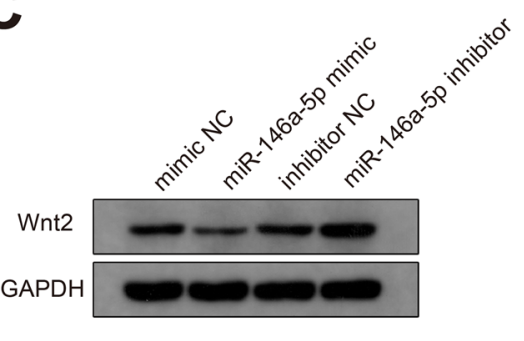

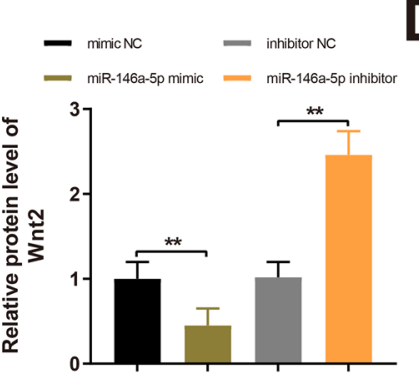

D

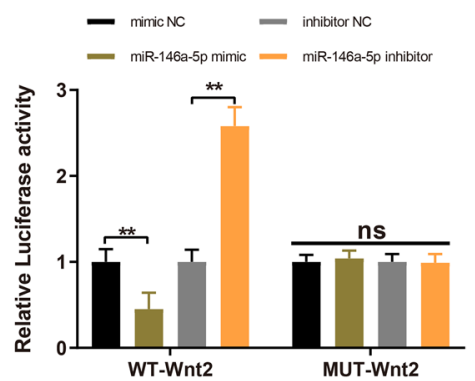

Fig. 4 miR-146a-5p targets Wnt2. Note: The binding sites of miR-146a-5p in the 3'UTR of Wnt2 were predicted by StarBase and the corresponding mutated target sites were designed (A). Following transfection of miR-146a-5p mimic, miR-146a-5p inhibitor, mimic NC or inhibitor NC into HTR-8 cells, the mRNA and protein levels of Wnt2 in HTR-8 cells were quantified by RT-qPCR and Western blotting (B, C). HEK-293 T cells were cotransfected with miR-146a-5p mimic or miR-146a-5p inhibitor and MUT-Wnt2 or WT-Wnt2, and the luciferase activity was determined by dual luciferase reporter assay (D). All data are presented as mean $\pm \mathrm{SD} ; \mathrm{n}=3$, ${ }^{*} \mathrm{P}<0.01$. SD standard deviation; $3^{\prime}$ UTR $3^{\prime}$ untranslated region

group); conversely, HEK-293 T cells cotransfected with WT-Wnt2 and miR-146a-5p inhibitor showed increased luciferase activity $(P<0.01$, vs the inhibitor NC group); the luciferase activities of cells cotransfected with MUTWnt2 and miR-146a-5p mimic/inhibitor displayed no significant difference when compared with the mimic NC or inhibitor NC group (Fig. 4D). Together, miR-146a-5p targeted and downregulated Wnt2.

miR-146a-5p regulates the propagation, invasion and EMT of trophoblast cells through Wnt2

To explore the implication of miR-146a-5p/Wnt2 axis in trophoblast cells, miR-146a-5p and/or Wnt2 was overexpressed in HTR-8 cells through transfection or cotransfection with mimic NC, miR-146a-5p or pcDNA3.1-Wnt2. As measured by RT-qPCR and Western blotting, Wnt2 expression in the miR-146a-5p mimic + pcDNA3.1-Wnt2 group was upregulated compared to the miR-146a-5p mimic + pcDNA3.1 group $(P<0.01)$; compared with the mimic NC group, Wnt2 expression was reduced in the miR-146a-5p mimic group $(P<0.01)$; while significant difference in Wnt2 expression was detected neither in the miR-146a-5p mimic group nor in the miR-146a-5p mimic + pcDNA3.1 group (Fig. 5A, B).

The proliferation of HTR-8 cells in the miR-146a-5p mimic + pcDNA3.1-Wnt2 group was enhanced compared to the miR-146a-5p mimic + pcDNA3.1 group $(P<0.01)$; in the miR-146a-5p mimic group, the proliferative capacity and the number of colonies were decreased than those in the mimic NC group $(P<0.05)$ (Fig. 5C, D). Also, the migratory and invasive capacities of HTR-8 cells cotransfected with miR-146a-5p mimic and pcDNA3.1-Wnt2 were promoted compared to the miR-146a-5p mimic + pcDNA3.1 group $(P<0.01)$, and cells in the miR-146a-5p mimic group showed inhibited migratory capacity and invasiveness compared to the mimic NC group $(P<0.05)$ (Fig. $5 \mathrm{E}$, $\mathrm{F})$. The differences in the malignant behaviors of HTR-8 cells were indistinctive between the miR-146a-5p mimic group and miR-146a-5p + pcDNA3.1 group.

As revealed by $\mathrm{RT}-\mathrm{qPCR}$ and Western blot analyses, Vimentin and N-cadherin levels were increased and E-cadherin expression was decreased in the miR-146a-5p mimic + pcDNA3.1-Wnt2 group $(P$ $<0.01$ ), and the levels of these EMT-related proteins were changed insignificantly in the miR-146a-5p mimic group, compared with the miR-146a-5p mimic + pcDNA3.1 group (Fig. 5G, H). These results indicated that Wnt2 overexpression could partially counteract the suppressive effects of miR-146a-5p mimic on HTR-8 cell propagation, invasion and migration as well as EMT process. Collectively, miR-146a-5p regulated 

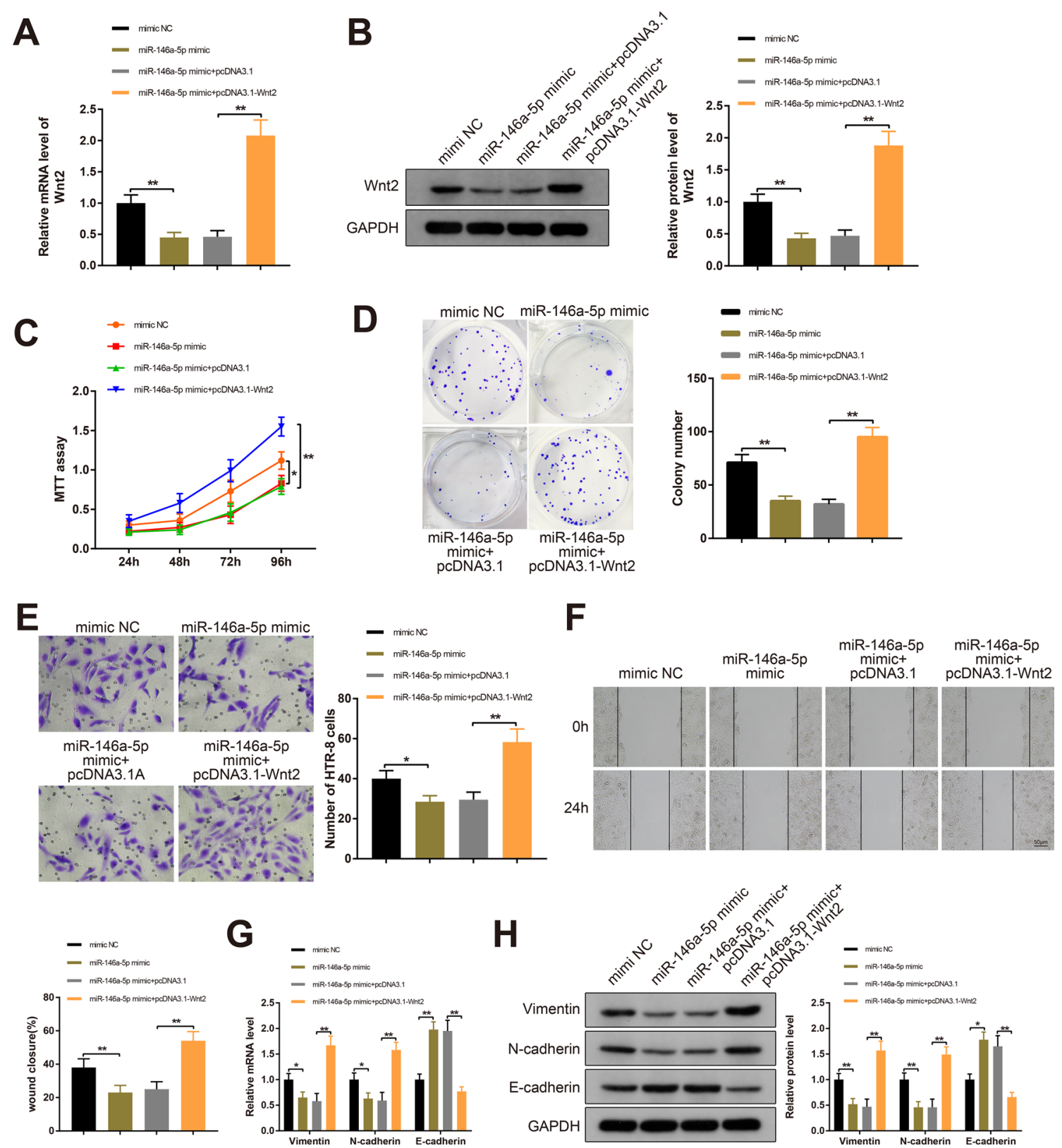

Fig. 5 miR-146a-5p regulates Wnt2 to affect trophoblast cell progression and EMT process. Note: After HTR-8 cells were transfected or cotransfected with miR-146a-5p mimic or pcDNA3.1-Wnt2, the mRNA and protein levels of Wnt2 were measured by RT-qPCR (A) and Western blotting (B); MTT assay and colony formation assay detected the proliferation of HTR-8 cells (C, D); invasiveness of HTR-8 cells as measured by Transwell invasion assay (E); HTR-8 cell migration was assessed by Scratch assay (F); RT-qPCR and Western blot analyses for EMT-related proteins $(\mathbf{G}$ H). All data are presented as mean $\pm \mathrm{SDs} ; \mathrm{n}=3,{ }^{*} P<0.05,{ }^{* *} P<0.01$. SD standard deviation; EMT epithelial-mesenchymal transition

trophoblast cell progression and EMT process through Wnt2.

\section{Discussion}

Recently, considerable attention has been paid on the regulation of miRNAs on trophoblast cell invasion and migration in PE $[24,25]$. However, the golden standard for PE treatment is still unavailable. To this end, we adopt this study to validate whether the regulatory mechanism of trophoblast cell migration, invasion and EMT in PE is involved with miR-146a-5p/Wnt2 axis.

During embryo implantation, cytotrophoblasts invade the maternal decidua reaching the uterine arteries where they differentiate to an endothelial-like 
phenotype replacing the maternal vascular endothelial and smooth muscle cells [26]. Failure of trophoblast cells to adequately invade and remodel spiral arteries might induce PE [27]. EMT is a biological process featured by the breakdown of cell-cell adhesion, loss of epithelial phenotypes and cell depolarization [28], and is responsible for normal morphogenetic processes including embryonic development, remodeling and would repair [29]. E-cadherin is a marker of EMT and an integral composition of cell-cell adhesion [29]. Invasion of trophoblast cells to the interstitial tissue of the decidua manifests as a loss of E-cadherin [30]. Intriguingly, miR-146a-5p is well documented as a regulator of cell invasive and migratory capacities. Reportedly, it inhibits cancer cell migration and invasion, impairs the expression of mesenchymal markers (Vimentin, N-cadherin and fibronectin) and promotes the expression of epithelial marker E-cadherin [31]. miR-146a-5p presents anti-migratory effect on prostate cancer cells partially through targeting Rac1 [32]. More importantly, endogenous miR-146a-5p expression was detected in HTR-8 cells $[15,33]$. Overexpression of miR-146a decreased the number of invaded trophoblast cells [34]. miR-146a-5p could be transferred by extracellular vesicles secreted by M1 macrophages into trophoblast cells to suppress cell migration and invasion by targeting TRAF6 [15]. Conversely, decreased miR$146 a-5 p$ expression was reported to be associated with PE requiring termination of gestation before 34 weeks [14]. These findings indicate that the genetic polymorphism of miR-146a-5p might be related to PE severity. In this paper, miR-146a-5p was upregulated in the placentae from PE patients. Moreover, we demonstrated that miR-146a-5p overexpression induced reductions in the proliferative, migratory and invasive capacities of trophoblast cells. In addition, the trophoblast cells presented augmented E-cadherin expression and weakened Vimentin and N-cadherin expression after miR-146a-5p overexpression. Collectively, we confirmed that miR146a-5p exhibited suppressive functions on trophoblast cell invasion, migration and EMT. Mechanistically, sirtuin 2 (SIRT2) deacetylated p65 to suppress miR146a expression, thereby increasing the proliferation, invasion and migration of trophoblast cells [35]. TNFrelated apoptosis-inducing ligand (TRAIL) induced trophoblast cell invasion through downregulating miR-146a and upregulating CXCR4, EGFR and matrix metalloproteinase 2 (MMP2) [34]. Of note, inflammation, hypoxia and oxidative stress has been revealed to affect trophoblast invasion [36-38]. Dysregulated miR146a expression was noticed in patients with recurrent pregnancy loss, concurrent with increased inflammatory and oxidative stress responses [39], and it could attenuate oxygen-glucose deprivation/reoxygenationinduced cardiomyocyte apoptosis [40]. Therefore, it could be an interesting topic to evaluate the impact of miR-146a-5p on trophoblast cell invasion from the perspectives of inflammatory, hypoxia and oxidative stress.

Wnt2, a secreted glycoprotein that functions through autocrine or paracrine modes, is found to express in villous syncytiotrophoblast and EVT, especially in the former [41]. Ye et al. [42] uncovered that Bisphenol A exposure disrupted trophoblast cell invasion and intervened the placental vessel remodeling, consequently leading to PE-like characteristics in pregnant mice, via mediating Wnt2 expression. Herein, our data confirmed a decrease in Wnt2 expression in placental tissues from PE patients. Upregulated Wnt2 enhanced the proliferative, migratory and invasive capacities and promoted the EMT process in trophoblast cells, and silencing of Wnt2 presented converse functions on the trophoblast cells. Consistently, Zhou et al. [43] demonstrated that Wnt2 expression was positively related to metastasis and EMT in cervical cancer. Moreover, this study further identified the binding relationship between miR-146a-5p and Wnt2 by employing bioinformatics analysis and dual luciferase reporter assay. Specifically, miR-146a-5p bound to the 3'UTR of Wnt2 and downregulated Wnt2 expression. Further gain- or loss-of-function assays exhibited that Wnt2 upregulation rescued the invasive and migratory properties of trophoblast cells in the presence of miR-146a-5p overexpression. It could be concluded that Wnt2 overexpression neutralized, in part, the suppressive effects of miR-146a-5p on trophoblast cell proliferation and invasion. Long noncoding RNA AV310809 was demonstrated to promote the EMT process of human peritoneal mesothelial cells through activating the Wnt2/ $\beta$-catenin pathway by targeting $\beta$-catenin [44]. In the transduction of canonical Wnt/ $\beta$-catenin pathway, Wnt protein activation results in translocation of $\beta$-catenin, a subunit of the cell surface cadherin protein complex, into the nucleus, and in turn, it acts as a co-factor of transcription factors [45]. Wnt/ $\beta$-catenin pathway reportedly regulates morphogenesis, gene transcription, differentiation and proliferation in cells [46]. Slug, Vimentin, MMPs and other downstream genes of $\mathrm{Wnt} / \beta$-catenin pathway are considered key players in EMT process [47]. In the process of early metastasis, cancer cells undergo EMT event regulated by $\mathrm{Wnt} / \beta$-catenin pathway [48]. Zhang and colleagues pointed out that forkhead box protein $\mathrm{H} 1$ (FOXH1) could encourage EMT through activating the Wnt $/ \beta$-catenin pathway, thus promoting lung cancer progression [49]. Moreover, resveratrol might induce EMT in trophoblast cells through the Wnt/ $\beta$-catenin pathway to increase trophoblast cell invasion [28]. It is reasonable to speculate that Wnt2 might induce the translocation 
of $\beta$-catenin into the nucleus of trophoblast cells, while it requires more extensive experiments to identify this hypothesis.

\section{Conclusion}

Our data manifested that miR-146a-5p was upregulated in the preeclamptic placentae. Through in vitro function assays, miR-146a-5p was proven to impair trophoblast cell proliferation, invasiveness and migratory capacity through inhibiting Wnt2. Further investigations regarding the role of miR-146a-5p in the initiation of PE would be anticipated. This study with respect to miR-146a-5pmediated trophoblast cell invasive and migratory capacities might provide novel insight into the diagnosis and treatment of PE.

\section{Acknowledgements}

Thanks for all the contributors.

\section{Authors' contributions}

QJF and PPP conceived the ideas. QJF and PPP designed the experiments. SHM; XCH; ZWF and MHG performed the experiments. XDD and ZJQ analyzed the data. YXQ; $C A H$ and TJ provided critical materials. XCH and SHM wrote the manuscript. QJF supervised the study. All the authors have read and approved the final version for publication.

\section{Funding}

Not applicable.

\section{Availability of data and materials}

The datasets used or analyzed during the current study are available from the corresponding author on reasonable request.

\section{Declarations}

\section{Ethics approval and consent to participate}

Committee approval from the First People's Hospital of Yichang was obtained after informed written consent was provided by each patient. This study conformed to the principles issued in the Declaration of Helsinki.

\section{Consent for publication}

Not applicable.

\section{Competing interests}

The authors declare that they have no competing interests.

\section{Author details}

${ }^{1}$ Department of Gynecology and Obstetrics, the First People's Hospital of Yichang, Yichang 443000, Hubei, People's Republic of China. ${ }^{2}$ Department of Gynecology and Obstetrics, the People's Hospital of China Three Gorges University, Yichang 443000, Hubei, People's Republic of China. ${ }^{3}$ Department of Gynecology and Obstetrics, the First People's Hospital of Yichang, the People's Hospital of China Three Gorges University, No. 4, Hudi Street, Xiling District, Yichang 443000, Hubei, People's Republic of China.

Received: 10 April 2021 Accepted: 24 August 2021

Published online: 13 September 2021

\section{References}

1. Shen XY, Zheng LL, Huang J, Kong HF, Chang YJ, Wang F, et al. CircTRNC18 inhibits trophoblast cell migration and epithelial-mesenchymal transition by regulating miR-762/Grhl2 pathway in pre-eclampsia. RNA Biol. 2019;16(11):1565-73.

2. Bailey LJ, Alahari S, Tagliaferro A, Post M, Caniggia I. Augmented trophoblast cell death in preeclampsia can proceed via ceramide-mediated necroptosis. Cell Death Dis. 2017;8(2):e2590.

3. Zuo Q, Huang S, Zou Y, Xu Y, Jiang Z, Zou S, et al. The Lnc RNA SPRY4IT1 modulates trophoblast cell invasion and migration by affecting the epithelial-mesenchymal transition. Sci Rep. 2016;6:37183.

4. Canfield J, Arlier S, Mong EF, Lockhart J, VanWye J, Guzeloglu-Kayisli O, et al. Decreased LIN28B in preeclampsia impairs human trophoblast differentiation and migration. FASEB J. 2019;33(2):2759-69.

5. Ge H, Yin N, Han TL, Huang D, Chen X, Xu P, et al. Interleukin-27 inhibits trophoblast cell invasion and migration by affecting the epithelial-mesenchymal transition in preeclampsia. Reprod Sci. 2019;26(7):928-38.

6. Yang X, Meng T. MicroRNA-431 affects trophoblast migration and invasion by targeting ZEB1 in preeclampsia. Gene. 2019;683:225-32.

7. Yu L, Kuang LY, He F, Du LL, Li QL, Sun W, et al. The role and molecular mechanism of long noncoding RNA-MEG3 in the pathogenesis of preeclampsia. Reprod Sci. 2018;25(12):1619-28.

8. Yang Y, Li H, Ma Y, Zhu X, Zhang S, Li J. MiR-221-3p is down-regulated in preeclampsia and affects trophoblast growth, invasion and migration partly via targeting thrombospondin 2. Biomed Pharmacother. 2019;109:127-34

9. Zou AX, Chen B, Li QX, Liang YC. MiR-134 inhibits infiltration of trophoblast cells in placenta of patients with preeclampsia by decreasing ITGB1 expression. Eur Rev Med Pharmacol Sci. 2018;22(8):2199-206.

10. Xu Y, Wu D, Jiang Z, Zhang Y, Wang S, Ma Z, et al. MiR-616-3p modulates cell proliferation and migration through targeting tissue factor pathway inhibitor 2 in preeclampsia. Cell Prolif. 2018;51(5):e12490.

11. Long JP, Dong LF, Chen FF, Fan YF. miR-146a-5p targets interleukin-1 receptor-associated kinase 1 to inhibit the growth, migration, and invasion of breast cancer cells. Oncol Lett. 2019;17(2):1573-80.

12. Wang C, Zhang W, Zhang L, Chen X, Liu F, Zhang J, et al. miR-146a-5p mediates epithelial-mesenchymal transition of oesophageal squamous cell carcinoma via targeting Notch2. Br J Cancer. 2016;115(12):1548-54.

13. Hromadnikova I, Kotlabova K, Dvorakova L, Krofta L. Postpartum profiling of microRNAs involved in pathogenesis of cardiovascular/cerebrovascular diseases in women exposed to pregnancy-related complications. Int J Cardiol. 2019;291:158-67.

14. Hromadnikova I, Kotlabova K, Hympanova L, Krofta L. Gestational hypertension, preeclampsia and intrauterine growth restriction induce dysregulation of cardiovascular and cerebrovascular disease associated microRNAs in maternal whole peripheral blood. Thromb Res. 2016;137:126-40.

15. Ding J, Zhang $Y$, Cai $X$, Zhang $Y$, Yan S, Wang J, et al. Extracellular vesicles derived from M1 macrophages deliver miR-146a-5p and miR-146b-5p to suppress trophoblast migration and invasion by targeting TRAF6 in recurrent spontaneous abortion. Theranostics. 2021;11(12):5813-30.

16. Zhang L, Leng M, Li Y, Yuan Y, Yang B, Li Y, et al. Altered DNA methylation and transcription of WNT2 and DKK1 genes in placentas associated with early-onset preeclampsia. Clin Chim Acta. 2019;490:154-60.

17. Li N, Li S, Wang Y, Wang J, Wang K, Liu X, et al. Decreased expression of WNT2 in villi of unexplained recurrent spontaneous abortion patients may cause trophoblast cell dysfunction via downregulated Wnt/betacatenin signaling pathway. Cell Biol Int. 2017;41(8):898-907.

18. Brkic J, Dunk C, O'Brien J, Fu G, Nadeem L, Wang YL, et al. MicroRNA218-5p promotes endovascular trophoblast differentiation and spiral artery remodeling. Mol Ther. 2018;26(9):2189-205.

19. Nasser MW, Qamri Z, Deol YS, Smith D, Shilo K, Zou X, et al. Crosstalk between chemokine receptor CXCR4 and cannabinoid receptor CB2 in modulating breast cancer growth and invasion. PLOS ONE. 2011;6(9):e23901.

20. Burja B, Kuret T, Janko T, Topalovic D, Zivkovic L, Mrak-Poljsak K, et al. Olive leaf extract attenuates inflammatory activation and DNA damage in human arterial endothelial cells. Front Cardiovasc Med. 2019;6:56.

21. Toliopoulos IK, Simos YV, Oikonomidis S, Karkabounas SC. Resveratrol diminishes platelet aggregation and increases susceptibility of K562 tumor cells to natural killer cells. Indian J Biochem Biophys. 2013;50(1):14-8.

22. Zheng $\mathrm{H}$, Kang Y. Multilayer control of the EMT master regulators. Oncogene. 2014;33(14):1755-63. 
23. Liang X. EMT: new signals from the invasive front. Oral Oncol. 2011;47(8):686-7.

24. Gao Y, She R, Wang Q, Li Y, Zhang H. Up-regulation of miR-299 suppressed the invasion and migration of HTR-8/SVneo trophoblast cells partly via targeting HDAC2 in pre-eclampsia. Biomed Pharmacother. 2018;97:1222-8

25. Wang F, Yan J. MicroRNA-454 is involved in regulating trophoblast cell proliferation, apoptosis, and invasion in preeclampsia by modulating the expression of ephrin receptor B4. Biomed Pharmacother. 2018;107:746-53.

26. Gutierrez J, Aedo A, Mora J, Maldonado J, Salsoso R, Toledo F, et al. Preeclampsia associates with RECK-dependent decrease in human trophoblasts migration and invasion. Placenta. 2017;59:19-29.

27. Zhang D, Liu H, Zeng J, Miao X, Huang W, Chen H, et al. Glucocorticoid exposure in early placentation induces preeclampsia in rats via interfering trophoblast development. Gen Comp Endocrinol. 2016;225:61-70.

28. Zou Y, Li S, Wu D, Xu Y, Wang S, Jiang Y, et al. Resveratrol promotes trophoblast invasion in pre-eclampsia by inducing epithelial-mesenchymal transition. J Cell Mol Med. 2019;23(4):2702-10.

29. Sun $Y Y, L u M, X i X W$, Qiao QQ, Chen $L L$, Xu XM, et al. Regulation of epithelial-mesenchymal transition by homeobox gene DLX4 in JEG-3 trophoblast cells: a role in preeclampsia. Reprod Sci. 2011;18(11):1138-45.

30. Batistatou A, Makrydimas G, Zagorianakou N, Zagorianakou P, Nakanishi Y, Agnantis NJ, et al. Expression of dysadherin and E-cadherin in trophoblastic tissue in normal and abnormal pregnancies. Placenta. 2007;28(5-6):590-2

31. Si C, Yu Q, Yao Y. Effect of miR-146a-5p on proliferation and metastasis of triple-negative breast cancer via regulation of SOX5. Exp Ther Med. 2018;15(5):4515-21

32. Sun Q, Zhao X, Liu X, Wang Y, Huang J, Jiang B, et al. miR-146a functions as a tumor suppressor in prostate cancer by targeting Rac1. Prostate. 2014;74(16):1613-21.

33. Yang C, Lim W, Park J, Park S, You S, Song G. Anti-inflammatory effects of mesenchymal stem cell-derived exosomal microRNA-146a-5p and microRNA-548e-5p on human trophoblast cells. Mol Hum Reprod. 2019;25(11):755-71.

34. Xiao C, Rui Y, Zhou S, Huang Y, Wei Y, Wang Z. TNF-related apoptosisinducing ligand (TRAIL) promotes trophoblast cell invasion via miR146a-EGFR/CXCR4 axis: a novel mechanism for preeclampsia? Placenta. 2020;93:8-16

35. Yu Y, An X, Fan D. Histone deacetylase sirtuin 2 enhances viability of trophoblasts through p65-mediated microRNA-146a/ACKR2 axis. Reprod Sci. 2021;28(5):1370-81.

36. Cheng SB, Nakashima A, Huber WJ, Davis S, Banerjee S, Huang Z, et al. Pyroptosis is a critical inflammatory pathway in the placenta from early onset preeclampsia and in human trophoblasts exposed to hypoxia and endoplasmic reticulum stressors. Cell Death Dis. 2019;10(12):927.

37. Hu H, Jiang J, Chen Q, Wei S, Liu M, Chen X, et al. Cyclophilin A inhibits trophoblast migration and invasion in vitro and vivo through p38/ERK
JNK pathways and causes features of preeclampsia in mice. Life Sci. 2020;261:118351.

38. Chen $\mathrm{CP}$, Chen $\mathrm{CY}, \mathrm{Wu}$ YH, Chen $\mathrm{CY}$. Oxidative stress reduces trophoblast FOXO1 and integrin beta3 expression that inhibits cell motility. Free Radic Biol Med. 2018;124:189-98.

39. Azizi R, Soltani-Zangbar MS, Sheikhansari G, Pourmoghadam Z, Mehdizadeh A, Mahdipour M, et al. Metabolic syndrome mediates inflammatory and oxidative stress responses in patients with recurrent pregnancy loss. J Reprod Immunol. 2019;133:18-26.

40. Zhang W, Shao M, He X, Wang B, Li Y, Guo X. Overexpression of microRNA-146 protects against oxygen-glucose deprivation/recovery-induced cardiomyocyte apoptosis by inhibiting the NF-kappaB/TNF-alpha signaling pathway. Mol Med Rep. 2018;17(1):1913-8.

41. Zhang Z, Zhang L, Zhang L, Jia L, Wang P, Gao Y. Association of Wnt2 and sFRP4 expression in the third trimester placenta in women with severe preeclampsia. Reprod Sci. 2013;20(8):981-9.

42. Ye $Y$, Tang $Y$, Xiong Y, Feng L, Li X. Bisphenol A exposure alters placentation and causes preeclampsia-like features in pregnant mice involved in reprogramming of DNA methylation of WNT2. FASEB J. 2019:33(2):2732-42

43. Zhou Y, Huang Y, Cao X, Xu J, Zhang L, Wang J, et al. WNT2 promotes cervical carcinoma metastasis and induction of epithelial-mesenchymal transition. PLoS ONE. 2016;11(8):e0160414.

44. Wei X, Huang H, Bao Y, Zhan X, Zhang L, Guo R, et al. Novel long non-coding RNA AV310809 promotes TGF-beta1 induced epithelial-mesenchymal transition of human peritoneal mesothelial cells via activation of the Wnt2/beta-catenin signaling pathway. Biochem Biophys Res Commun. 2019;513(1):119-26

45. Monga SP. beta-catenin signaling and roles in liver homeostasis, injury, and tumorigenesis. Gastroenterology. 2015;148(7):1294-310.

46. Kretzschmar $\mathrm{K}$, Clevers $\mathrm{H}$. Wnt/beta-catenin signaling in adult mammalian epithelial stem cells. Dev Biol. 2017;428(2):273-82.

47. Zhang Y, Hua PY, Jin CY, Li JD, Zhang GX, Wang B. JMJD3 enhances invasiveness and migratory capacity of non-small cell lung cancer cell via activating EMT signaling pathway. Eur Rev Med Pharmacol Sci. 2019;23(11):4784-92.

48. Zhao YR, Wang JL, Xu C, Li YM, Sun B, Yang LY. HEG1 indicates poor prognosis and promotes hepatocellular carcinoma invasion, metastasis, and EMT by activating Wnt/beta-catenin signaling. Clin Sci. 2019;133(14):1645-62.

49. Zhang J, Zhang X, Yang S, Bao Y, Xu D, Liu L. FOXH1 promotes lung cancer progression by activating the Wnt/beta-catenin signaling pathway. Cancer Cell Int. 2021;21(1):293.

\section{Publisher's Note}

Springer Nature remains neutral with regard to jurisdictional claims in published maps and institutional affiliations.
Ready to submit your research? Choose BMC and benefit from:

- fast, convenient online submission

- thorough peer review by experienced researchers in your field

- rapid publication on acceptance

- support for research data, including large and complex data types

- gold Open Access which fosters wider collaboration and increased citations

- maximum visibility for your research: over 100M website views per year

At $\mathrm{BMC}$, research is always in progress.

Learn more biomedcentral.com/submissions 